Legislative Coalitions in a Bargaining Model with Externalities

Randall L. Calvert and Nathan Dietz

Working Paper No. 16

July 1998
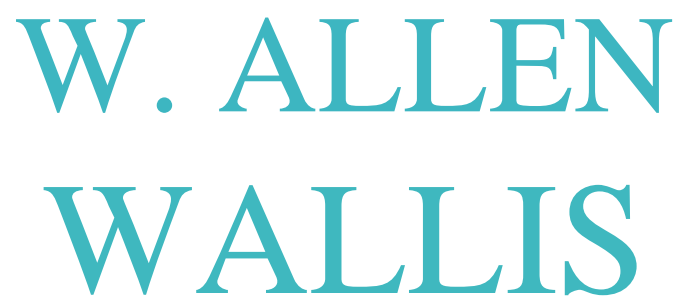

Institute of
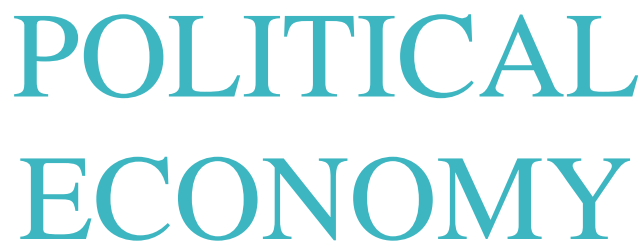

UNIVERSITY OF

ROCHESTER 


\title{
Legislative Coalitions in a Bargaining Model with Externalities
}

\author{
Randall L. Calvert and Nathan Dietz \\ University of Rochester
}

August 1996

\begin{abstract}
Previous work modeling a legislature in which bill proposals and voting take a form analogous to offer-counteroffer bargaining offer a new view of what legislative parties are and why they are formed. However, such models either represent preferences as being purely distributive in nature, so that there are no variations in preference similarity across legislators and thus no reason for any particular group of legislators to form a party; or else used a full spatial model of legislative preferences, which lacks tractability. To gain the advantages from both approaches, this paper analyzes a distributive model with simple externalities. The model is employed to gain an improved understanding of the conditions under which legislative parties can be said to effect outcomes beyond what could be expected from purely myopic, rational behavior among legislators with similar preferences.
\end{abstract}

draft 1.2

This paper was prepared for presentation at the annual meetings of the American Political Science Association, August 29-Sept. 1, 1996, San Francisco. The authors are grateful to David Austen-Smith and to seminar participants at Duke University, Harvard University, and Northwestern University for comments on material that preceded this paper. 


\title{
Legislative Coalitions in a Bargaining Model with Externalities
}

\author{
Randall L. Calvert and Nathan Dietz
}

\section{Introduction}

The recent literature on political parties in Congress features a renewed interest in the nature of parties and new ideas for understanding parties in terms of the political motivations of legislators. Several analysts (Aldrich 1995; Cox and McCubbins 1993; Kiewiet and McCubbins 1991; Rohde 1991) have suggested that parties are designed by legislators to overcome complex problems of delegation, collective action, or coalition building in the legislature, and discussed the design of parties, the behavior of members in the

context of legislative parties, and the affects of such parties on legislative structure and legislative

outcomes. By and large, these studies have constructed or sketched models of a fairly complex legislative

process within which the delegation, collective action, and coalition building problems occur.

A few authors, however, have tackled the problem of party organization among rational legislators in different ways. Baron and Ferejohn (1989) take a more stripped-down approach to the modeling of the legislative process, portraying it simply as a series of distributional offers proposed by individual members and accepted or rejected by a vote of the legislative body. In this context, Baron $(1989,1991)$ proceeds to develop the idea of a party as an agreement allowing a given coalition to control legislative outcomes at the expense of nonmembers of the coalition.

In an entirely different vein, Krehbiel (1993) questions how we should interpret legislative party as a phenomenon separate from simple rational behavior of individual legislators with similar preferences. He argues that we cannot draw conclusions about the effect, and effectiveness, of parties simply from the observation that legislators having consistently similar goals exhibit consistently similar voting choices; those legislators would be expected to vote similarly anyway, and the proponent of party significance in legislative outcomes must show that parties play a role beyond simply naming a group of members with similar preferences. Krehbiel believes that parties are significant only to the extent that "individual legislators vote with fellow party members in spite of their disagreement about the policy in question" (1993, 238). It is possible, however, that the independent effect of parties lies instead in the nature of the bills that are presented for voting, rather than in the voting decisions of legislators, as suggested by Snyder's (1992) account of the basis for apparent unidimensionality in roll-call voting. If we want to resolve the question of whether parties have a significant effect on legislative outcomes, independently of legislator preferences, it is necessary to explain how individual members not organized by parties would generate bills for voting as well as how those members would vote. The purpose of this paper is to contribute to such an explanation.

Baron's initial portrayal of legislation as an extended bargaining process (1989; Baron and Ferejohn 1989) is not suitable for addressing the issues raised by Krehbiel, since legislative bills in those models are matters of pure distribution: each proposal would simply divide a fixed "pie" among the members, and each legislator cares only about the size of his or her own slice. In that setting, there can be no interesting patterns of preference similarity. Even so, Baron identifies a motivation for legislators to form parties in that setting: by being a member of a coalition whose members always make proposals favoring the coalition at the expense of nonmembers, the individual gains a higher expected payoff. Aldrich (1995) discusses this same motivation in a different theoretical context; such considerations go back ultimately to the reasoning of Buchanan and Tullock (1962, chapters 9-11) that majority rule allows a majority coalition to exploit a minority coalition.

Baron (1991), however, extends the "bargaining" model of legislatures to the choice of positions in a multidimensional policy space, over which the participants have quadratic preferences. The stated purpose 
of that model is to examine the process of coalition formation among parties in a parliamentary government; the same model would in principle be ideal for examining proposals and voting patterns in any legislature. With such a model, one could depict patterns of similarity in the policy goals of legislators, and determine the extent to which such legislators might exhibit party-like similarities in voting without the benefit of any real party mechanisms to control their voting or bill-proposing behavior. Unfortunately, calculations in the Baron (1991) model become intractable in all but the simplest settings. Baron is able to derive closed-form solutions for stationary equilibria of proposal and voting strategies only for certain very restrictive special cases having only three or four legislators and a specific layout of ideal points. In this paper, we propose a model that retains a bit more of the simplicity of the pure-distribution setting but still allows for the depiction of preference similarities among legislators. This model allows us

to begin to distinguish conceptually between true party-driven legislative behavior and the purely preference-driven, faux-party behavioral similarities recognized by Krehbiel. Our main accomplishment in this paper is to clarify Krehbiel's idea of what ought to be the baseline from which party significance is assessed, using a model that incorporates proposals of bills, as well as voting, among otherwise unorganized rational legislators.

\section{Bargaining Models of Legislative Politics}

In their original bargaining model of legislative politics, Baron and Ferejohn (1989) set up a simple legislative game having two distinguishing features. First, the only task of the legislature is to decide on the division of a fixed stock of resources among its members. All members value their own allocation of this stock in the same way; none receives any utility from resources allocated to other members. Second, legislative procedure is explicitly modeled as a process of recognition of a member to propose a division of the stock, followed by voting on that proposal. If a proposal passes, the legislators realize their payoffs and the game ends. If not, the game continues with another round of recognition and voting. Baron and Ferejohn consider several variants on this simple procedure in order to study the effects of closed rules, amendment processes, and the like. For present purposes, it suffices to consider the simplest version of their model. ${ }^{1}$

The Baron-Ferejohn legislature consists of a set of members $L=\{1,2, \ldots, n\}$ where $n=2 m-1$ for some integer $\mathrm{m}$, so $\mathrm{m}$ is the size of a minimal majority and $\mathrm{n}$ is an odd number. An outcome of the legislative process is any distribution $\mathrm{x}=\left(\mathrm{x}_{1}, \ldots, \mathrm{x}_{\mathrm{n}}\right)$ of shares of a fixed stock of resources, with each $\mathrm{x}_{\mathrm{j}} \geq 0$ and $\sum_{\mathrm{L}}$ $\mathrm{x}_{\mathrm{j}}=1$. Each legislator $\mathrm{i}$ receives utility from a distribution $\mathrm{x}$ simply equal to $\mathrm{x}_{\mathrm{i}}$. The game form consists of the following parliamentary procedure "stage game," repeated if necessary:

(1) A legislator is recognized at random to propose a distribution. In this recognition process, legislator $\mathrm{i}$ is recognized with probability $p_{i}$, with each $p_{j} \geq 0$ and $\sum_{\mathrm{L}} \mathrm{p}_{\mathrm{j}}=1$.

(2) The legislature votes on the proposal, with all members voting simultaneously.

(3) If a majority votes for the proposal, the game ends and players receive their payoffs; otherwise, the stage game is repeated starting at (1). Note that the legislator who made the failed proposal is eligible to be recognized again.

Baron and Ferejohn define a stationary strategy $s_{i}$ for legislator $i$ in this game as consisting of:

1 Aside from the two-period example that they introduce for illustrative purposes. The model described here is the potentially infinite-period, "closed-rule" model with no discounting. 
(1) a proposal rule, describing what proposal $x^{i}=\left(x_{1}{ }^{i}, \ldots, x_{n}{ }^{i}\right)$ player i will make whenever recognized; and

(2) a voting rule, such as "Vote in favor of any proposal having $\mathrm{x}_{\mathrm{i}} \geq \mathrm{y}$, and against any other," which specfies how the player will vote on any proposal.

Such strategies are "stationary" in that they are not contingent on the history of play in the game, that is, on previous unsuccessful proposals, who made them, or how various members voted on them. (Of course,

non-stationary strategies are possible too; we will have more to say about these subsequently.) A stationary equilibrium in this game is a profile of stationary strategies $s=\left(s_{1}, \ldots, s_{n}\right)$ for which, for each i,

(1) i could not get a better expected outcome by proposing some other $\mathrm{x}^{\mathrm{i} *}$ at any point;

(2) i could not get a better expected outcome by voting otherwise on any proposal at any point;

(3) i's strategy is not weakly dominated (due to its voting rule specifying a vote that would harm i if i's vote were pivotal, in an outcome in which i is in fact not pivotal); and

(4) conditions (1)-(3) hold in every possible subgame (subgame perfection).

Baron and Ferejohn prove that the following properties hold for any stationary equilibrium:

(1) the proposing player always offers $x_{j}^{i}=1 / n$ to each player in some randomly chosen group of $m-1$ players, keeps $1-(\mathrm{m}-1) / \mathrm{n}$ for herself, and offers the others zero;

(2) each player i always votes for any proposal offering $i$ at least $1 / \mathrm{n}$ and against any other proposal;

(3) in equilibrium, the first proposal made is always accepted;

(4) ex ante, each player can expect to receive a payoff of $1 / n$; the player selected as the first proposer ends up receiving $1-(\mathrm{m}-1) / \mathrm{n}$

(5) any minimal winning coalition is as likely to form as any other.

In particular, property (5) indicates that there are no legislative parties in this game in any sense.

\section{Parties in Bargaining Models}

Baron and Ferejohn (1989) also examine briefly what can happen in their model when strategies are not stationary. They begin by assuming that players discount by some small factor any payoffs to be received from the next proposal, should the present one fail. With this proviso Baron and Ferejohn are able to prove a "folk theorem:" any distribution of the stock of resources can be supported as the outcome of some equilibrium strategy profile, provided that the discounting is sufficiently light and that $n \geq 5$. A distribution $\mathrm{x}$ is implemented through a strategy profile that punishes any player who proposes any other distribution $\mathrm{y} \neq \mathrm{x}$, as follows: some designated majority $\mathrm{M}(\mathrm{y})$ votes against the deviant proposal $\mathrm{y}$; the next proposer is to make a new proposal $\mathrm{z}(\mathrm{y})$ that gives all members of $\mathrm{M}(\mathrm{y})$ what they would have gotten in $\mathrm{y}$, plus a share of what the deviant would have gotten, and gives the deviant zero; and if that second proposer fails to propose $\mathrm{z}(\mathrm{y})$, the same sort of punishment is then directed at him, and punishment of the initial deviant is abandoned. Although Baron and Ferejohn do not examine parties explicitly in their paper, this result suggests the possibility that a sort of legislative party might be formed, since it is possible to implement a distribution in which a particular coalition would with certainty receive all of the stock of resources. We return subsequently to the related notion that a legislative party consists of a particular repeated-game equilibrium. 
In a subsequent paper Baron (1989) examines a related model that generates party-like behavior in a bargaining legislature, again restricting attention to stationary strategies. In this paper, ${ }^{2}$ Baron assumes that members of a coalition can commit perfectly in advance to making a certain proposal if recognized. By using this ability to commit to a proposal that, although it still may favor the proposer, distributes the remainder of the benefits only to members of the coalition, a majority "party" can ensure most benefits for itself. In this equilibrium, however, if a coalition non-member is recognized, that proposer will be able to pick off some coalition votes and get her proposal passed. Even so, as Baron shows, there is an advantage to being a member of such a coalition. ${ }^{3}$ Baron also demonstrates that if the players discount future payoffs to differing extents, some coalitions will offer a higher payoff advantage to their members than other coalitions will to theirs; in this sense, some groupings of legislators would make more sense as a "majority party" than others. However, this sort of legislative party lacks a feature of primary importance to parties in the real world: since all they are doing is dividing a pie, there is no particular policy-based reason for a legislator to prefer some coalition partners to others. In contrast, we normally think of parties as consisting of members who want something in common, and in contrast to party non-members.

In "A Spatial Bargaining Theory of Government Formation in Parliamentary Systems," Baron (1991) examines one further approach to understanding party formation through a bargaining model. Here, rather than dividing a fixed stock of resources, the players are engaged in choosing a point in a policy space in

which all have quadratic preferences; thus they are restricted in the ways they are able to divide the available policy benefits. Although the analysis is couched in terms of forming a coalition government in a parliamentary system, it speaks to legislative proposing and voting in exactly the same way as the model in

Baron (1989), with one important advantage: due to the relative locations of their ideal points, the legislators in a spatial bargaining model have more reason to coalesce with some of their colleagues than with others. Thus there could, in principle, be parties whose members have prior, common interests inherently opposed to those of non-members, beyond simple distributional jockeying. Unfortunately, calculation of equilibrium outcomes in the spatial bargaining model turns out to be extremely complicated. Baron is able to derive a closed-form solution only for the following special cases: (1) three players whose ideals are co-linear; (2) three players whose ideal points are all equidistant from one another, each having a $1 / 3$ chance of recognition; (3) three players whose ideal points form the vertices of an isosceles triangle, with the player whose ideal is equidistant from the other two never being recognized to propose; (4) four players, three at the vertices of an equilateral triangle and one at the center of the triangle, all having equal

2 As in the discussion of Baron and Ferejohn (1989), we confine attention to the closed-rule case, although Baron also examines a version in which legislators can propose amendments. Within the closedrule setting, Baron examines cases in which coalition members do and do not have the ability to commit themselves to "party discipline" in voting. Under party discipline, when a non-member makes a proposal, coalition members will vote for it only if it gives every coalition member the share he or she would get from a proposal by another coalition member. Here we examine only the non-discipline case, since it is most relevant to the question at hand; in this case, a non-member need not gain the votes of all coalition members simultaneously in order to pass a proposal.

${ }^{3}$ Baron's main result, and his purpose in this model, is to show that the optimal coalition in this setting will, generally, have more than members. This is because optimal coalition size must balance how thinly coalition proposals spread their benefits against the probability that a proposer outside the coalition will be recognized, resulting in a lower ex ante expected payoff to coalition members. 
probability of recognition. ${ }^{4}$ The results indicate that legislators whose ideal points are centrally located receive higher payoffs than others, and that legislators usually propose so as to attract the vote of the nearest colleague, but in equilibrium must sometimes propose so as to attract the vote of a more distant colleague instead.

\section{A Bargaining Model with Preference Similarities}

In order to gain additional analytical leverage on the problem while retaining the possibility of varying preference similarities among legislators, consider a variation on the Baron-Ferejohn, pure-distribution bargaining model of the legislature. Begin with the Baron-Ferejohn setting of a legislature L in which each member $i$ is recognized with probability $p_{i}$ to propose a distribution of a fixed stock of resources of size 1 . Now, however, let us broaden our assumption about the utility to a member of a particular distribution $\mathrm{x}$ of the stock, as follows:

$$
\mathrm{u}_{\mathrm{i}}(\mathrm{x})=\sum_{\mathrm{j} \in \mathrm{L}} \mathrm{a}_{\mathrm{ij}} \mathrm{x}_{\mathrm{j}}
$$

where $\mathrm{a}_{\mathrm{ii}}=1$ and, for $\mathrm{i} \neq \mathrm{j}, \mathrm{a}_{\mathrm{ij}} \leq 1$. Thus the share received by a player may affect the payoffs of other players to varying extents. The direct interpretation of this payoff function is that each legislator cares not only about his or her own allocation of the stock, but also to some extent about the shares of some other members. This would be the case, for example, if the good being distributed were not purely private but rather had spillover effects.

A utility function of this form could also result from other constructions. For example: (1) Legislators wish only to gain the approval of interest groups in their districts. Benefits are "distributed" not to legislators but to interest groups, with different legislators having different concentrations of the groups in their prospective election-winning coalitions at home. This utility function represents simply an adding up of the distributive payoffs to the various interest groups, weighted by the prevalence of that group in member i's constituency. (Obviously the model could be broadened to allow a the number of interest groups to differ from the number of legislators.) (2) This utility function approximates a spatial model.

The $\mathrm{a}_{\mathrm{ij}}$ are inverse distances between legislators' positions in some issue space, and the legislators' indifference curves are straight lines. (Again, obviously the dimensionality of the issue space could be made different from the number of legislators.)

Since this utility function is simpler in form than the quadratic preferences examined by Baron (1991), there is reason to hope that it will yield more extensive results, allowing us to say more about the nature of legislative parties. Thus far we have been able to obtain some improvement on Baron's results by deriving a closed-form solution to a general three-player case. In what follows, we present an illustrative special case, and then proceed to the analysis of the general three-legislator situation with symmetrical spillovers

$\left(\mathrm{a}_{\mathrm{ij}}=\mathrm{a}_{\mathrm{ji}}\right.$ always $)$. For simplicity we assume throughout the remainder of this paper that the legislators' probabilities of recognition are equal: $p_{i}=1 / n$.

\section{An Illustrative Case}

Let $\mathrm{L}=\{1,2,3\}$ and suppose that the only spillover effect is a symmetrical one between legislators 1 and 2 : that is, $\mathrm{a}_{12}=\mathrm{a}_{21}=\alpha$ for some $\alpha \in[0,1]$, while $\mathrm{a}_{13}=\mathrm{a}_{31}=\mathrm{a}_{23}=\mathrm{a}_{32}=0$. Thus for an allocation $\mathrm{x}=\left(\mathrm{x}_{1}, \mathrm{x}_{2}, \mathrm{x}_{3}\right)$, the players would receive the following payoffs:

${ }^{4}$ Baron also examines a couple of three-player cases in which the members make proposals in a sequence of recognition that is fixed in advance, a setting more relevant to the formation of parliamentary coalition governments than to the formation of voting coalitions on a bill. 


$$
\begin{gathered}
\mathrm{u}_{1}(\mathrm{x})=\mathrm{x}_{1}+\alpha \mathrm{x}_{2} \\
\mathrm{u}_{2}(\mathrm{x})=\alpha \mathrm{x}_{1}+\mathrm{x}_{2} \\
\mathrm{u}_{3}(\mathrm{x})=\mathrm{x}_{3}=1-\mathrm{x}_{1}-\mathrm{x}_{2} .
\end{gathered}
$$

Several of the main considerations of the Baron-Ferejohn model are important for solving this new game. First, given any profile of strategies for proposing and voting, we can calculate a continuation value for each player (i.e. the expected payoff from the remainder of the game as seen before anyone is recognized to make the next proposal). Second, we in order to have her proposal accepted, a player i must gain the vote of at least one other player $\mathrm{j}$ by offering $\mathrm{j}$ a large enough allocation to offset the possible gain to $\mathrm{j}$ from defeating i's proposal and perhaps being able to make j's own, more favorable proposal on the next round. Third, it never makes sense to offer a partner an allocation any amount beyond that just large enough to attract his vote. In equilibrium, exactly one player will make a proposal, and that first proposal will be accepted by a majority; off the equilibrium path, a subgame-perfect equilibrium will always feature majority acceptance of the next proposal. Now, however, because of the spillover effect, the third player may also gain utility from the proposed allocation. As we will see, this incidental gain will in general not be sufficient to gain the third player's vote as well. As in the previous analyses, then, the proposals in a stationary equilibrium can be calculated by setting each proposal exactly equal to the continuation value of the targeted player, and then solving for the proposed allocations and for each player's mixed-strategy probability of offering to each of the other players.

We first solve for the type of equilibrium that corresponds most closely to those derived by Baron and by Baron and Ferejohn: a stationary equilibrium in which all players use mixed strategies in a fashion that respects the symmetries assumed in the payoff functions. Accordingly, assume that legislator 3 , if recognized, attempts to gain the vote of either legislator 1 or 2 with equal probability, and that in either case 3 offers the same allocation, w, to the intended coalition partner (and zero to the other player). Players 1 and 2, meanwhile, will attempt to attract one another's support with probability p, and with probability 1-p will attempt to gain the support of player 3. When player 1 tries to attract player 2's support, she offers him an allocation of y (and nothing to player 3), and vice versa. When player 1 or 2 tries to attract the vote of player 3, they offer $\mathrm{z}$ to player 3 and nothing to one another.

These assumptions are sufficient to set up equations yielding a particular equilibrium to the game. First of all, the players' continuation values are as follows: for player 1,

$$
\begin{gathered}
\mathrm{V}_{1}=\mathrm{a}\left[\mathrm{pu}_{1}(1-\mathrm{y}, \mathrm{y}, 0)+(1-\mathrm{p}) \mathrm{u}_{1}(1-\mathrm{z}, 0, \mathrm{z})\right]+\mathrm{a}\left[\mathrm{pu}_{1}(\mathrm{y}, 1-\mathrm{y}, 0)+(1-\mathrm{p}) \mathrm{u}_{1}(0,1-\mathrm{z}, \mathrm{z})\right]+ \\
\mathrm{a}\left[1 / 2 \mathrm{u}_{1}(\mathrm{w}, 0,1-\mathrm{w})+1 / 2 \mathrm{u}_{1}(0, \mathrm{w}, 1-\mathrm{w})\right],
\end{gathered}
$$

where the three main terms correspond to the possibilities that player 1,2, or 3, respectively, will be making the next offer, and the two terms within each set of brackets corresponding to the two different pure-strategy actions that could be taken by that proposer. Substituting for $\mathrm{u}_{1}$ in this equation and simplifying yields

$$
\mathrm{V}_{1}=(1-\mathrm{z}+\mathrm{pz}+\mathrm{w} / 2)(1+\alpha) / 3
$$

Due to the symmetries in this case, $\mathrm{V}_{2}$ has the same formula. Using a similar method of calculation,

$$
\mathrm{V}_{3}=[2(1-\mathrm{p}) \mathrm{z}+1-\mathrm{w}] / 3 .
$$


Now each offer must yield the intended voting partner his continuation value. This means that the following equations must hold: for player 1's offer to player 2 ,

$$
\begin{gathered}
\mathrm{u}_{2}(1-\mathrm{y}, \mathrm{y}, 0)=\mathrm{V}_{2}, \\
\text { that is, } \\
\mathrm{y}+\mathrm{a}(1-\mathrm{y})=(1-\mathrm{z}+\mathrm{pz}+\mathrm{w} / 2)(1+\alpha) / 3 .(1)
\end{gathered}
$$

The same constraint applies to 2's offer to 1. For 1's or 2's offer to 3,

$$
\begin{gathered}
\mathrm{u}_{3}(1-\mathrm{z}, 0, \mathrm{z})=\mathrm{V}_{3} \text {, i.e., } \\
\mathrm{z}=[2(1-\mathrm{p}) \mathrm{z}+1-\mathrm{w}] / 3 .(2)
\end{gathered}
$$

Finally, 3's offer to 2 or 1 must satisfy

$$
\begin{gathered}
\mathrm{u}_{1}(\mathrm{w}, 0,1-\mathrm{w})=\mathrm{V}_{1} \text {, i.e., } \\
\mathrm{w}=(1-\mathrm{z}+\mathrm{pz}+\mathrm{w} / 2)(1+\alpha) / 3 .(3)
\end{gathered}
$$

Furthermore, the use of mixed strategies implies that each player must be precisely indifferent between offering to either of the other two. This yields the following constraints: for player 1, and equivalently for player 2,

$$
\begin{aligned}
\mathrm{u}_{1}(1-\mathrm{y}, \mathrm{y}, 0) & =\mathrm{u}_{1}(1-\mathrm{z}, 0, \mathrm{z}), \text { that is, } \\
1-\mathrm{z} & =1-\mathrm{y}+\alpha \mathrm{y}, \text { or, } \\
\mathrm{z} & =(1-\alpha) \mathrm{y} .(4)
\end{aligned}
$$

For player 3, the mixed-strategy constraint is always satisfied given our assumption that 3 offers the same allocation to 1 or 2 and that the two have the same spillover effect on 3 (namely, none).

Equation (4) immediately gives a solution for $z$ in terms of $y$. Since (1) and (3) have the same right-hand side, we can set their left-hand sides equal to get $\mathrm{w}=\mathrm{y}+\alpha(1-\mathrm{y})=\alpha+(1-\alpha) \mathrm{y}$. Substituting for $\mathrm{w}$ and $\mathrm{z}$ in terms of $y$ in (2) and (3) and solving simultaneously for $y$ and p, then, gives the following values of the strategy parameters in terms of $\alpha$ :

$$
\begin{gathered}
\mathrm{p}=(1+\alpha) / 2 \\
\mathrm{y}=1 /(\alpha+3) \\
\mathrm{z}=(1-\alpha) /(\alpha+3) \\
\mathrm{w}=\alpha+\mathrm{z}
\end{gathered}
$$


and of course $\mathrm{V}_{1}=\mathrm{V}_{2}=\mathrm{w}$ and $\mathrm{V}_{3}=\mathrm{z}$. Notice that the value of being the proposer is 1-w for player 3 and is 1$\mathrm{z}$ for players 1 and 2. A little calculation (using the assumption $\alpha \in[0,1]$ ) shows that for each player the payoff from being the proposer is strictly greater than the continuation value, so, as initially assumed, each player will prefer to make these successful offers when recognized rather than take the chance of passing along the proposal-making opportunity to another player. Since this condition is indeed satisfied, the solution is an equilibrium when combined with the voting strategy, "vote for any proposal that yields at least the continuation value."

The outstanding feature of this solution is that, when the value of $\alpha$ is reasonably large, legislators 1 and 2 will usually propose allocations that favor each other, so the apparent winning coalition will usually consist of those two. Consider some numerical examples:

First, $\alpha=0$ is the baseline case equivalent to the Baron-Ferejohn model. In that case, $p=1 / 2$, and $\mathrm{w}=\mathrm{y}=\mathrm{z}=1 / 3$ : the proposer chooses each of the other players with equal probability as a coalition partner, and offers that player 1/3 of the "pie," keeping 2/3 for herself. (See Baron and Ferejohn 1989, 1191-92). In this case, each of the three possible two-player coalitions forms the majority for passage with probability $1 / 3$.

If we introduce a modest amount of spillover between legislators 1 and 2, those two players begin to favor one another in their proposing behavior. Suppose $\alpha=1 / 4$. Then the computed solution gives $\mathrm{p}=5 / 8$, $\mathrm{w}=25 / 52, \mathrm{y}=4 / 13$, and $\mathrm{z}=3 / 13$. Legislators 1 and 2 offer to form the voting coalition with one another slightly more often than with legislator 3 ; they offer each other slightly more than they offer legislator 3 , and, when legislator 3 is recognized to propose the allocation, she has to offer even more in order to attract the vote of 1 or 2 . In this case, $\{1,2\}$ provides the majority for passage with probability $5 / 12$, and $\{1,3\}$ and $\{2,3\}$ form the majority with probability $7 / 24$ each.

A higher level of congruence between the preferences of players 1 and 2 makes them truly predominate as the winning coalition. Suppose $\alpha=1 / 2$. Then with probability $\mathrm{p}=3 / 4$, legislator 1 , when recognized, proposes to allocate 2/7 to legislator 2 and keep the rest for herself, and legislator 2 does the same. The proposer receives a payoff of 5/7 + (1/2)(2/7) or 6/7 from this arrangement, and the coalition partner receives $9 / 14$. Overall, $\{1,2\}$ form the majority for passage with probability $1 / 2$. With probability $1 / 4$, legislator 1 or 2 will make the offer to legislator 3 instead, offering only 1/7 to get 3's vote, and realizing a payoff of 6/7 while 3 gets $1 / 7$ (the left-out legislator, 2 or 1 respectively, realizes a payoff of 3/7 -- less than his continuation value, but, if we allow an interpersonal comparison of utility, more than 3 gets!). As $\alpha$ increases toward 1 , the probability that $\{1,2\}$ is the winning coalition increases toward $2 / 3$. However, in the extreme, if the payoffs of players 1 and 2 are equal $(\alpha=1)$, then they always propose to one another, and when legislator 3 is recognized, she can gain the vote of 1 or 2 only by offering one of them the whole pie--in which case both of them vote in favor of the proposal. This resembles the behavior of the "majority party" in Baron (1989), in that members of

the $\{1,2\}$ coalition propose exclusively to one another, but here their behavior involves no kind of commitment, enforced or otherwise, to propose only

to party colleagues or to vote only for party proposals. The party-like behavior is due simply to individual rational behavior in the presence of strong similarities of interest. Figure 1 graphs the probability of $\{1,2\}$ being the winning coalition (simply $2 \mathrm{p} / 3$ or $(1+\alpha) / 3)$ against the value of $\alpha$. 


\section{The General Three-Legislator Model}

Now consider the general three-legislator case with equal probabilities of recognition and symmetric

spillovers. That is, $\mathrm{L}=\{1,2,3\}, \mathrm{p}_{\mathrm{i}}=1 / 3, \mathrm{a}_{12}=\mathrm{a}_{21}=\alpha, \mathrm{a}_{23}=\mathrm{a}_{32}=\beta$, and $\mathrm{a}_{13}=\mathrm{a}_{31}=\gamma$. To identify the set of stationary, fully mixed-strategy equilibria we can use essentially the same method as in the special case above, and as used by Baron and Ferejohn and by Baron. Let $\mathrm{p}$ be legislator 1's probability of offering to player 2, let q be player 2's probability of offering to player 1, and let $r$ be player 3's probability of offering to player 1. Finally, let $\mathrm{x}_{\mathrm{ij}}$ be the share that player i proposes to allocate to player $\mathrm{j}$. The continuation values can be expressed as follows:

$$
\begin{gathered}
3 \mathrm{~V}_{1}=\mathrm{p}\left[1-(1-\alpha) \mathrm{x}_{12}\right]+(1-\mathrm{p})\left[1-(1-\gamma) \mathrm{x}_{13}\right]+\mathrm{q}\left[\alpha+(1-\alpha) \mathrm{x}_{21}\right]+ \\
(1-\mathrm{q})\left[\alpha+(\gamma-\alpha) \mathrm{x}_{23}\right]+\mathrm{r}\left[\gamma+(1-\gamma) \mathrm{x}_{31}\right]+(1-\mathrm{r})\left[\gamma+(\alpha-\gamma) \mathrm{x}_{32}\right] \\
3 \mathrm{~V}_{2}=\mathrm{p}\left[\alpha+(1-\alpha) \mathrm{x}_{12}\right]+(1-\mathrm{p})\left[\alpha+(\beta-\alpha) \mathrm{x}_{13}\right]+\mathrm{q}\left[1-(1-\alpha) \mathrm{x}_{21}\right]+ \\
(1-\mathrm{q})\left[1-(1-\beta) \mathrm{x}_{23}\right]+\mathrm{r}\left[\beta+(\alpha-\beta) \mathrm{x}_{31}\right]+(1-\mathrm{r})\left[\beta+(1-\beta) \mathrm{x}_{32}\right] \\
3 \mathrm{~V}_{3}=\mathrm{p}\left[\gamma+(\beta-\gamma) \mathrm{x}_{12}\right]+(1-\mathrm{p})\left[\gamma+(1-\gamma) \mathrm{x}_{13}\right]+\mathrm{q}\left[\beta+(\gamma-\beta) \mathrm{x}_{21}\right]+ \\
(1-\mathrm{q})\left[\beta+(1-\beta) \mathrm{x}_{23}\right]+\mathrm{r}\left[1-(1-\gamma) \mathrm{x}_{31}\right]+(1-\mathrm{r})\left[1-(1-\beta) \mathrm{x}_{32}\right] .
\end{gathered}
$$

The requirement that an offer intended to solicit a player's vote yield that player his continuation value defines six continuation-value constraints that the equilibrium must satisfy:

$$
\begin{aligned}
& \alpha+(1-\alpha) x_{21}=V_{1}(C V 1) \\
& \gamma+(1-\gamma) x_{31}=V_{1}(C V 2) \\
& \alpha+(1-\alpha) x_{12}=V_{2}(C V 3) \\
& \beta+(1-\beta) x_{32}=V_{2}(C V 4) \\
& \beta+(1-\beta) x_{23}=V_{3}(C V 5) \\
& \gamma+(1-\gamma) x_{13}=V_{3}(C V 6)
\end{aligned}
$$

The indifference constraints for mixed strategies are:

$$
\begin{aligned}
& 1-(1-\alpha) x_{12}=1-(1-\gamma) x_{13}(\text { MS } 1) \\
& 1-(1-\alpha) x_{21}=1-(1-\beta) x_{23}(\text { MS2 }) \\
& 1-(1-\gamma) x_{31}=1-(1-\beta) x_{32}(M S 3)
\end{aligned}
$$

Using MAPLE, a computer program for symbolic manipulation of equations, we obtained the following solution to the system of equations (CV1)-(CV6) and (MS1)-(MS3):

$$
q=\frac{-\alpha+\beta+\gamma-1}{\gamma-1}\left(\frac{(\alpha-1) r}{-\alpha-\beta+\gamma+1}+1\right)
$$




$$
\begin{aligned}
& \left.p=\frac{-\alpha+\beta+\gamma-1}{(\beta-1)(\alpha-\beta+\gamma-1)}[(\alpha-1) r+\gamma-\beta)\right] \\
& x_{12}=\frac{(1-\beta)(\alpha-\beta+\gamma-1)^{2}}{(\alpha-1) D} \\
& x_{13}=\frac{(1-\beta)(\alpha-\beta+\gamma-1)^{2}}{(\gamma-1) D} \\
& x_{21}=\frac{(1-\gamma)(-\alpha-\beta+\gamma+1)^{2}}{(\alpha-1) D} \\
& x_{23}=\frac{(1-\gamma)(-\alpha-\beta+\gamma+1)^{2}}{(\beta-1) D} \\
& x_{31}=\frac{(1-\alpha)(-\alpha+\beta+\gamma-1)^{2}}{(\gamma-1) D} \\
& x_{32}=\frac{(1-\alpha)(-\alpha+\beta+\gamma-1)^{2}}{(\beta-1) D} \\
& D=\alpha^{2}+\beta^{2}+\gamma^{2}-2 \alpha \beta-2 \alpha \gamma-2 \beta \gamma+2 \alpha+2 \beta+2 \gamma-3 \\
& =(-\alpha+\beta+\gamma-1)^{2}-4(1-\beta)(1-\gamma) \text {. }
\end{aligned}
$$

Notice that this equilibrium has one free parameter among the probability variables; here, it is taken to be the probability $\mathrm{r}$. As is always the case for equilibria in the Baron-Ferejohn model, in this model particular values of $\alpha, \beta$, and $\gamma$ often yield a whole family of fully mixed equilibria (parameterized here by $\mathrm{r}$ ), whose members differ in the probabilities with which each member makes an offer designed to attract the vote of each other member. Across the equilibria in this family, the offer values $\mathrm{x}_{\mathrm{ij}}$ and the continuation payoffs $\mathrm{V}_{\mathrm{i}}$

are unchanging. Changing one of the mixed-strategy probabilities while keeping the $\mathrm{V}_{\mathrm{i}}$ constant necessitates offsetting changes in the other mixed-strategy probabilities.

This effect is most easily illustrated using the equilibrium in the case of $\beta=\gamma=0$ computed above; there we assumed in effect that $r=.5$, but different values of $r$ would also have generated equilibria, albeit with different values for the other mixed-strategy probabilities (which would no longer be equal). In particular, letting $\mathrm{r}$ take on different values gives the following generalized formulas for $\mathrm{p}$ and $\mathrm{q}: \mathrm{p}=(\alpha+1) \mathrm{r}$ and $\mathrm{q}=$ $(\alpha+1)(1-r)$. Thus a higher probability of 3 offering to 1 is offset by a higher probability of 1 offering to 2 and a lower probability of 2 offering to 1 . Note that, unlike what happens in the Baron-Ferejohn model, there are limits to how far we can vary $r$ : if $r$ lies outside the interval $[1 /(\alpha+1), \alpha /(\alpha+1)]$ then either $p$ or $q$

will no longer be a valid probability. Similar limits apply to our general fully mixed equilibrium.

Existence of Fully Mixed Equilibria 
Contrary to what happened in either the Baron-Ferejohn model or in the equilibrium we computed for the special case of $\beta=\gamma=0$, fully-mixed equilibria in our general game may fail to exist for all values of $r$; and for certain values of $\alpha, \beta$, and $\gamma$, there may be no fully mixed equilibrium at all. ${ }^{5}$ This happens when the offer values or mixed-strategy probabilities given by the formulas above are outside the admissible range $[0,1]$. To get an idea of the combination of parameter values for which fully mixed equilibrium exists, consider what happens when $\alpha=\beta$. Inspection of the formula for $\mathrm{p}$ above reveals that when $\alpha=\beta, \mathrm{p}$ is a decreasing linear function of $\gamma$, equal to one when $\gamma=(1-\alpha) r+2 \alpha-1$ and equal to zero when $\gamma=(1-\alpha) r+\alpha$. Thus $\gamma$ must lie between these two values in order to yield a valid $p$ for the mixed strategy. When $\alpha=\beta, q$ is a slightly more complicated function of $\gamma$, having a singularity at $\gamma=2 \alpha-1$. Below that value, however, $\mathrm{q}$ is

always greater than 1 , so we can focus on $\gamma$-values above the singularity point. In that region, $\mathrm{q}$ is increasing; it reaches the value 0 at $\gamma=(1-\alpha) r+2 \alpha-1$ and asymptotes to 1 (unless $\alpha=\beta=1$, in which case $q=1$ identically). Thus we get a valid probability $\mathrm{q}$ in all cases in which $\mathrm{p}$ is valid.

We can do similar calculations for the values of the offers made by the players, which also must lie between 0 and 1 , inclusive. When $\alpha=\beta, x_{12}$ and $x_{32}$, which are identical, lie in $[0,1]$ for all values of $\gamma$ that yield valid q-values. The values of $x_{13}$ and $x_{31}$, which are identical, are positive only when $\gamma$ is above the singularity point of $4 \alpha-3$; there, the offer values are monotonically declining in $\gamma$, reaching 1 when $\gamma=3 \alpha-2$, and asymptoting to 0 . Thus any $\gamma$ above $3 \alpha-2$ generates valid offer values. Finally, $x_{21}$ and $x_{23}$ are identical and equal to a rather complicated fraction of polynomials even when $\alpha=\beta$. However, it is still easy to calculate that these two offers are valid exactly when $\gamma$ meets two conditions: first, $\gamma \geq 4 \alpha-3$ (which is less than the lower bound for $\mathrm{x}_{13}$ and $\left.\mathrm{x}_{31}\right)$; and second, $\gamma^{2}+(3 \alpha+1) \gamma+3 \alpha-2 \leq 0$. The latter condition, required for the offer values to be no greater than 1, is satisfied when $\alpha$ and $\gamma$ are not too large; for example, if $\gamma=1$ then $\alpha$ must be zero, and vice-versa; and if $\alpha, \beta$, and $\gamma$ are all equal, then their value must be no greater than

$$
\frac{\sqrt{3}-1}{2} \text {, or } 0.37 \text {. }
$$

The upshot of all this is that, when $\alpha=\beta \leq 1 / 3$, fully mixed equilibria exist only when $\gamma$ is not too large; and if $\alpha=\beta>1 / 3, \gamma$ must be neither too large nor too small. The more general lesson is that if any of the three parameters is large, that is, if any of the legislators' consumption externalities is great, then all externalities must be similar in magnitude in order for the fully mixed equilibrium to exist. The leeway available to these three parameter values also depends upon the value of the free mixed-strategy probability $r$ that is used: higher values of $\alpha$ and $\beta$ require lower values of $r$ in order to allow a maximum-sized range for $\gamma .{ }^{6}$

This general behavior can be illustrated through numerical analysis of the formulas for fully mixed equilibria. If all three parameters take on moderate or small values, there is more leeway for them to differ. For example, if $\alpha=.05, \beta=.25$, and we consider equilibria with $\mathrm{r}=.75$ (which is among the most favorable $\mathrm{r}$ values) then all values of $\gamma$ from zero up to 0.8 generate valid strategies. ${ }^{7}$ If $\alpha=.25, \beta=.5$, and $\mathrm{r}=.5$, then $\gamma$

5 An example of the latter phenomenon occurs when $\alpha=.1, \beta=.5, \gamma=.9$, where the computed value for $\mathrm{q}$ is negative for all values of $\mathrm{r}$ in $[0,1]$.

${ }^{6}$ Numerical analysis indicates that the limiting factor is the generation of $\mathrm{p}$ - and q-values between 0 and 1 ; in all the examples we have constructed with $\alpha \neq \beta \neq \gamma$, whenever $p$ and $q$ are valid probabilities, the values of the all the $\mathrm{x}_{\mathrm{ij}}$ are also valid. We have been unable to prove this as a general fact, however, and it seems likely that in extreme cases one or more of the offer values could be independently constraining.

${ }^{7}$ For smaller values of $r$, the range of $\gamma$ generating valid strategies is more restricted and often more complicated. For r-values of .5 or less, valid strategies result from sufficiently small or sufficiently 
values from about .1 to .75 generate valid strategies, only a slightly smaller range. ${ }^{8}$ If $\alpha=.7$ and $\beta=.8$, valid strategies result only when $\gamma$ is between about .58 and .9 even for the most favorable r-values, around $.25 .{ }^{9}$

\section{Other Stationary Equilibria in the General Three-Legislator Game}

We have examined the possibility that stationary, partially mixed or pure strategy equilibria might exist in the general three-legislator model. No such equilibria exist in the Baron-Ferejohn model except as extreme members of the family of fully mixed equilibria, that is, equilibria that satisfy all the continuation-value

constraints and mixed-strategy indifference constraints, but that happen to have one or more of the probabilities equal to 0 or 1 (in the Baron-Ferejohn model, necessarily either all or none of the probabilities would be strictly between 0 and 1.) The existence of externalities in our model complicates the matter, and we have been unable thus far to prove analytically that such additional equilibria do not exist apart from the fully mixed class, that is, equilibria that are not fully mixed and do not satisfy all the constraints (CV1)-

(CV6) and (MS1)-(MS3).

On the other hand, we have also tried but failed to identify any such partially mixed stationary equilibria. Such equilibria would have to obey any relevant constraints from the full set above. In addition, an equilibrium pure strategy (i.e. a strategy that specifies making offers exclusively to one of the other players) for any player would have to satisfy the condition that there is no way for that player to offer to the other potential partner instead, giving that new partner at least his continuation value and retaining enough "pie" to be better off than if she had offered to the partner originally specified by the pure strategy. Although we can identify many pure and partially-mixed strategies that satisfy the relevant constraints, all have thus far failed this equilibrium test.

The possibility remains that there may be non-stationary equilibria even for the values of $\alpha, \beta$, and $\gamma$ incompatible with stationary, fully mixed equilibrium. If the "folk theorem" of Baron and Ferejohn is any indication, there will in fact be many non-stationary equilibria.

large $\gamma$ values (although always only for $\gamma \leq 0.8$ ), but not for values in the middle. When $r=.25$, for instance, valid strategies result from $\gamma$ of .4 and below, near .8, but not in the neighborhood of .6. For all r-values, .8 is the exact upper limit of $\gamma$-values allowing fully-mixed equilibrium.

${ }^{8}$ Here too, for some $\mathrm{r}$ the range of allowable $\gamma$ may be in two pieces. For $\mathrm{r}=.1, \gamma$-values around 0.67 fail to generate valid strategies, although gamma from zero up to that neighborhood, and also between that neighborhood and .75, do generate valid strategies. For all r-values, .75 is the exact upper limit of $\gamma$ values allowing fully mixed strategies.

${ }^{9}$ For such large values of $\alpha$ and $\beta$, only small values of $r$ seem to cause the above-mentioned bifurcation of the range of on which fully-mixed equilibrium exists. At $r=.1$, fully mixed equilibrium exists for all $\gamma$ from .53 to .9 , except for a tiny interval around $\gamma=.85$. For higher $r$-values, the range of compatible $\gamma$ becomes a single interval that shrinks as $r$ increases; for $r=.9$, fully mixed equilibria exist only for $\gamma$ between about .78 and .9. Whatever the value of $r$, the exact upper bound on compatible $\gamma$ is .9. 
"Parties" under Fully Mixed, Stationary Equilibrium

We can now examine the appearance of consistent proposing and voting blocs in the general three-legislator model, generalizing our earlier description of party-like behavior in the illustrative case where two of the externality parameters were set to zero. In the family of fully mixed equilibria for any given $\alpha, \beta$, and $\gamma$, the continuation payoffs for all three players are fixed. However, by and large a player sharing stronger externalities with others enjoys a higher expected payoff. Moreover, if one pair of players shares stronger externalities than the others, that pair will tend to form the winning coalition more often than the others. As a result, in repeated legislative

\begin{tabular}{|l|l|l|l|l|l|}
\hline $\mathrm{r}$ & $\mathrm{p}$ & $\mathrm{q}$ & $\operatorname{Pr}(1,2)$ & $\operatorname{Pr}(1,3)$ & $\operatorname{Pr}(2,3)$ \\
\hline 0.273 & 0.375 & 1.000 & 0.458 & 0.299 & 0.242 \\
\hline 0.3 & 0.413 & 0.963 & 0.458 & 0.296 & 0.246 \\
\hline 0.4 & 0.550 & 0.825 & 0.458 & 0.283 & 0.258 \\
\hline 0.5 & 0.688 & 0.688 & 0.458 & 0.271 & 0.271 \\
\hline 0.6 & 0.825 & 0.550 & 0.458 & 0.258 & 0.283 \\
\hline 0.7 & 0.963 & 0.413 & 0.458 & 0.246 & 0.296 \\
\hline 0.727 & 1.000 & 0.375 & 0.458 & 0.242 & 0.299 \\
\hline
\end{tabular}

Table 3: Probability of each winning coalition, as a function of the equilibrium mixed-strategy probabilities, when $\alpha=.5$ and $\beta=\gamma=.2$. interactions, that pair of players may behave as though they were an imperfect party, even though they have no internal organization beyond their mutual expectation about stationary equilibrium. behavior. There is really no effect of party as such; rather, the predominance of one voting coalition, and their tendency to propose policies they mutually desire at the expense of the other player, is purely the result of individual myopic, rational action.

To illustrate these effects clearly, we consider a few specific cases in which the externality within two of the legislator pairs is identical and relatively small, and that in the other pair is relatively large. First, suppose that $\alpha=.5$ while $\beta=\gamma=.2$. These parameter values allow a family of equilibria parameterized by $r$, where $\mathrm{r}$ ranges from about .273 to .727 . As Table 1 indicates, the probability with which $\{1,2\}$ forms the winning coalition is .458 for any value of $r$, while the other two winning coalitions appear with probabilities between .242 and .299; larger $r$ are offset by larger $\mathrm{p}$ and smaller q. The situation is really symmetric from the standpoint of legislator 3--she has the same level of shared interest with each of them.

If we set $r=.5$ accordingly, then we see that legislators 1 and 2 make their offers to one another with probability .688 each. Once again, this resembles (imperfectly) the behavior of "parties" in Baron (1989), but involves no kind of commitment to propose to party colleagues or to vote only for party proposals. Table 2 illustrates how this party-like behavior varies when we vary the strength of the externality between 1 and 2 and the difference between it and the strength of the externality between them and legislator 3 . Either increasing the externality between 1 and 2 or decreasing the common externality between 1 and 3 and between 2 and 3 increases the expected frequency with which $\{1,2\}$ appears as the winning coalition. When $\alpha=.9$ while $\beta=\gamma=.1$, this probability reaches as high as .63. For those externality levels, legislators 1 and 2 are offering to each other with probability .944 each; when they do offer to legislator 3 , they allocate him only 0.029 , and when 3 proposes, he has to allocate .917 of the "pie" to legislator 1 or 2 in order to gain their vote. 


\begin{tabular}{|c|c|c|c|}
\hline$\alpha$ & $\beta=\gamma$ & $\operatorname{Pr}(1,2)$ & $\operatorname{Pr}(1,3)=\operatorname{Pr}(2,3)$ \\
\hline 0.5 & 0.2 & 0.458 & 0.271 \\
\hline 0.6 & 0.2 & 0.500 & 0.250 \\
\hline 0.7 & 0.2 & 0.542 & 0.229 \\
\hline 0.8 & 0.2 & 0.583 & 0.208 \\
\hline & & & \\
\hline 0.8 & 0.1 & 0.593 & 0.204 \\
\hline 0.8 & 0.2 & 0.583 & 0.208 \\
\hline 0.8 & 0.3 & 0.571 & 0.214 \\
\hline 0.8 & 0.4 & 0.556 & 0.222 \\
\hline 0.8 & 0.5 & 0.533 & 0.233 \\
\hline 0.8 & 0.6 & 0.500 & 0.250 \\
\hline 0.8 & 0.7 & 0.444 & 0.278 \\
\hline & & & 0.185 \\
\hline 0.9 & 0.1 & 0.630 & \\
\hline & & & \\
\hline
\end{tabular}

Table 4: Probability of each winning coalition, as a function of the externality parameters, when $\beta=\gamma$ and $\mathbf{r}=.5$.

\section{Discussion}

The above examples indicate that party-like behavior may in principle be a consequence of nothing more than preference similarity. When two players are more similar in preferences to one another and less similar to the third, as indicated by the externality parameters, the similar players propose "bills" that favor each other disproportionately often, and vote so as to form the eventual winning coalition with a higher probability than do other possible coalitions. When the relative similarity between the two players is large, this party-like effect is fairly dramatic. If an analyst were to observe roll-call votes from repetitions of such a legislative situations, and the two similar players had been previously labeled as a "party," the frequency with which they vote together might fool the analyst into thinking that some significant form of party action underlay their voting. If the analyst also had a means of observing the proposals made and how favorable those proposals were to the various legislators, he might be even more inclined to invoke party as an explanation of legislative outcomes.

Keith Krehbiel would rightly object. The observed voting patterns would be completely the result of legislators having similar preferences about bills.

And the erstwhile party analyst could not respond that this is only because parties controlled the proposal process, generating proposals that exploited certain divisions among legislators while papering over others. Rather, even the party-favoring proposals in the modeled world are generated by legislators acting independently, solely in their own interests, without any organizing, gatekeeping, or sanctioning by a party hierarchy.

We have no intention of arguing, however, that parties are not important, even in the U.S. Congress, even perhaps at the modern nadir of party voting in the 1970s. The models we have begun to analyze here serve to clarify the baseline for attributing of significance to parties, combining the analysis of endogenous proposals and voting as pioneered by Baron and Ferejohn (1989) with the possibility of varying preference similarities, which, as Krehbiel (1993) makes clear, are basic to evaluating the independent effect of party. It is entirely possible that a version of our with a realistic number of legislators would require much larger differences between within- and across-group externalities in order to generate high probabilities of the majority "party" providing the winning coalition; perhaps only extreme preference similarities and differences would generate the kind of false party effects that Krehbiel discusses, and the appropriate baseline level of party voting would be much lower. There is no reason to conclude that preferences alone will be sufficient to account for legislative outcomes as we observe them in modern American and 
The main promise of the model we present, however, lies in clarifying this party baseline in a context in which real parties themselves can also be modeled in a fully endogenous manner. Institutions such as legislative parties can be productively studied through models that portray the institution as a feature of equilibrium behavior in an appropriately chosen underlying game (Calvert 1995). This might be accomplished in the one-bill legislative bargaining game studied here, or even better, in a model of repeated legislative sessions. Baron (1989) merely assumes that members of his parties can commit themselves to proposing only bills that concentrate all benefits on the party. As we have seen, extreme preference similarities could lead to behavior substantially like this even in stationary equilibrium. ${ }^{10}$ But real partiesas-equilibrium-institutions would go further than this, employing sanctions across stages of the game (nonstationary equilibria) to enforce a higher level of party-favoring proposals than could be assured by preference similarities alone. In such an equilibrium, a party member who fails to propose as prescribed could be cut out of the coalition in future iterations and replaced by a party non-member waiting in the wings, similar to the device used in the Baron-Ferejohn "folk theorem" to enforce an arbitrary pattern of benefit distribution.

The examination of repeated-game models of real party behavior is a matter for future research. For now, based on what we have learned from the present model, we are inclined to elaborate on Krehbiel's (1993, 236) definition of "significant party behavior" in the following terms: Legislatively significant parties, theoretically speaking, are nonstationary equilibrium institutions in the legislative game that use retaliation and coordination mechanisms to make members propose and vote in a manner contrary to what they would do in a stationary equilibrium.

${ }^{10}$ Since a selection among multiple equilibria is necessary to reach this state of affairs in our model, one might be tempted to say that even our stationary equilibrium represents a basic sort of party institution. But we would have to maintain the Krehbiel no-real-party line in this case: as our examples show, in the ideal case of one large externality and two smaller ones all of the equilibria exhibit the same degree of party-like behavior; moreover, failure to coordinate on one of these equilibria would present no real problem, since there is no need to identify and punish deviation from the equilibrium path. The result, in observational terms, would simply be added noise in the frequency of the off-"party" coalitions and in the frequency of intra- and inter-"party" offers made by individual legislators. 


\section{References}

John H. Aldrich. 1995. Why Parties? (Chicago: University of Chicago Press).

David P. Baron. 1989. "A Noncooperative Theory of Legislative Institutions," American Journal of Political Science 33, pp. 1048-84.

----------. 1991. "A Spatial Bargaining Theory of Government Formation in Parliamentary Systems," American Political Science Review 85, pp. 137-64.

and John A. Ferejohn. 1989. "Bargaining in Legislatures," American Political Science Review 83, pp. 1181-1206.

James M. Buchanan and Gordon Tullock. 1962. The Calculus of Consent (Ann Arbor: University of Michigan Press).

Randall L. Calvert. 1995. "Rational Actors, Equilibrium, and Social Institutions." In J. Knight and I. Sened, eds., Explaining Social Institutions (Ann Arbor: University of Michigan Press).

Gary W. Cox and Mathew D. McCubbins. 1993. Legislative Leviathan (Berkeley: University of California Press).

D. Roderick Kiewiet and Mathew D. McCubbins. 1991. The Logic of Delegation (Chicago: University of Chicago Press).

Keith Krehbiel. 1993. "Where's the Party?" British Journal of Political Science 23, pp. 235-66.

David W. Rohde. 1991. Parties and Leaders in the Postreform House (Chicago: University of Chicago Press).

James M. Snyder, Jr. 1992. "Committee Power, Structure-Induced Equilibria, and Roll Call Votes," American Journal of Political Science 36, pp. 1-30. 